\title{
Building Partnerships by Bridging Cultures, Contexts, and Systems - Reflections on TEPE 2015
}

MARCO SNOEK ${ }^{1}$

\section{Building bridges}

Building partnerships implies building bridges between different and sometimes isolated worlds. And building bridges is something the Scots are good at! However, passing the famous and impressive Forth Bridge and approaching Dundee, I was also reminded that bridges can collapse, as the nearby Tay Rail Bridge did in 1879 . So there was no better place to have the annual conference of the Teacher Education Policy in Europe Network than Dundee. They know the importance of building sustainable bridges between different worlds. Without such bridges, no partnerships between these worlds are possible.

\section{Input and inspiration}

The conference theme 'Building Partnerships' was elaborated in three keynote presentations, over 70 presentations, a panel discussion, and many professional dialogues during the breaks. Professor Hannele Niemi, the chair of the TEPE board, identified teacher education as part of an ecosystem, in which different actors and subsystems are dependent on each other. One actor or subsystem cannot survive without relations with other actors in the educational world or in society as a whole. Professor Kari Smith from Norway did a great job by creating a conceptual framework during the first keynote as a starting point for the discussions. She emphasised the importance of shared goals, shared responsibilities, mutual respect, and shared power. From her experience with teacher education in Norway, she gave inspiring examples of partnerships at different levels, such as the Norwegian national $\mathrm{PhD}$ school for teacher educators (NAFOL) and the international forum for teacher educator development (INFOTED).

On the second day, Professor Ronald Sultana from Malta emphasised the perspective from Southern Europe, where education is a matter of life and death. In this context, collaboration with partners outside the world of

1 Centre of Applied Research in Education, Amsterdam University for Applied Sciences,

Netherlands; m.snoek@hva.nl. 
education is essential. NGOs can be of great value in strengthening the societal responsibility and social engagement of (teacher) education. In the third keynote, Gillian Hamilton gave a concrete example of to where partnerships can lead by presenting the Scottish College for Educational Leadership.

Partnerships can bridge several subsystems. The keynotes illustrated that partnerships in teacher education can focus on relations between teacher education institutes and

- $\quad$ students

- $\quad$ other departments within universities

- other higher education institutions

- $\quad$ international partners

- the practice field

- teachers and teacher councils

- $\quad$ policy makers

- NGOs

- $\quad$ and (tomorrow's) society as a whole.

This broad variety of partnership was illustrated by presentations during the four rounds of parallel sessions offering a wide source of inspiration and food for thought for the participants.

\section{Personal reflections}

It is impossible to summarise all the discussions that took place during the keynotes, the parallel sessions, the panel and during the breaks. So I will restrict myself to some personal reflections and questions that came up during the conference, and that require further discussion within or outside the TEPE network.

First of all, my impression is that we need a stronger analysis of the dynamics and conceptual elements of partnerships. For me, the concepts of boundaries and boundary crossing (Akkerman \& Bakker, 2011; Engeström, 2001; Wenger, 1998) are helpful in this. In my opinion, building a partnership is not about integrating two subsystems into one, nor is it about formal agreements and criteria that need to be met to be considered as a partner in a partnership. However, it is about creating spaces for a shared professional dialogue where participants from different subsystems meet, exchange their understandings and interpretations of issues and create opportunities for mutual learning based on mutual respect. Several presentations referred to such 'third spaces' (Zeichner, 2010) or 'boundary zones'. I think that it is essential to elaborate 
how such third spaces and boundary zones can be developed, and to identify and share successful examples. This is especially necessary in the partnership between teacher education institutes and policy makers, which is the key focus of the Teacher Education Policy in Europe Network. The relation between TEIs and policy makers is problematic in many countries. However, during the conference, several examples of 'collaborative policy making' were presented, such as the collaborative response that was given to the Donaldson report in Scotland, and the European Commission's working group Schools where policy makers and teacher educators engage in learning dialogues on key policy issues.

Another key topic for partnership is the partnership between universities. Kari Smith opened with the quote from Churchill: 'United we stand, divided we fall'. In several countries, teacher education is under pressure. When universities attempt to withstand this pressure on their own, they will fail. Only when universities join forces and are collectively willing to take responsibility for the quality of teacher education in a country as a whole will they provide a valid and convincing answer for policy makers. To provide that valid and convincing answer we need to understand the concerns of policy makers and ministers, but we need to provide our own answers to these concerns, answers that are informed by research and do justice to the key challenge for education: to support the development of children in terms of knowledge, skills, values, and identity. Governments, ministries and policy makers are concerned with answers that guarantee the system-wide quality of education. The response of universities also needs to cover such a system-wide perspective and can't restrict itself to institutional levels.

When universities adapt themselves to the dominant market approach and participate in the competition rat race in getting students and research funds, they are doomed to lose their collective voice. Kari Smith again showed how Norwegian universities were able to change the rules by refusing to enter into competition by drawing up, nationwide, a shared proposal for a $\mathrm{PhD}$ research school for teacher educators that could not be ignored by the government.

Several presentations showed how teacher education institutes are under pressure. In part, this pressure can be explained by the failure of teacher education institutes to have a shared voice towards policy makers and to show how they perform at a system-wide level. Of course, this is not only a challenge for teacher education institutes, but also for policy makers. After all, a partnership is a responsibility of two partners. Teacher education institutes and policy makers are connected to each other. How the two systems of teacher education practice and teacher education policy can be bridged in such a way that the 
bridge will not collapse, and that connections can be turned into commitment, can be a key topic for the next TEPE conference.

\section{References}

Akkerman, S., \& Bakker, A. (2011). Boundary crossing and boundary objects. Review of Educational Research, 81(2), 132-169.

Engeström, Y. (2001). Expansive learning at work: Toward an activity theoretical reconceptualization. Journal of Education and Work, 14(1), 133-156.

Wenger, E. (1998). Communities of practice: Learning, meaning, and identity. Cambridge:

Cambridge University Press.

Zeichner. K. (2010). Rethinking the connections between campus courses and field experiences in college- and university-based teacher education. Journal of Teacher Education, 61(1-2), 89-99.

\section{Biographical note}

MARCo SNOEK is professor Teacher Learning and School Innovation, Centre of Applied Research in Education, Amsterdam University for Applied Sciences, and a member of the TEPE board. 